\title{
Identifying and reducing disparities in successful addiction treatment completion: testing the role of Medicaid payment acceptance
}

\author{
Erick G. Guerrero ${ }^{1 *}$ D, Bryan R. Garner ${ }^{2}$, Benjamin Cook $^{3}$, Yinfei Kong ${ }^{4}$, William A. Vega ${ }^{5}$ and Lillian Gelberg ${ }^{6}$
}

\begin{abstract}
Background: Medicaid has become the largest payer of substance use disorder treatment and may enhance access to quality care and reduce disparities. We tested whether treatment programs' acceptance of Medicaid payments was associated with reduced disparities between Mexican Americans and non-Latino Whites.

Methods: We analyzed client and program data from 122 publicly funded treatment programs in 2010 and 112 programs in 2013. These data were merged with information regarding 15,412 adult clients from both periods, of whom we selected only Mexican Americans $(n=7130,46.3 \%)$ and non-Latino Whites $(n=8282,53.7 \%)$. We used multilevel logistic regression and variance decomposition to examine associations and underlying factors associated with Mexican American and White differences in treatment completion. Variables of interest included client demographics; drug use severity and mental health issues; and program license, accreditation, and acceptance of Medicaid payments.

Results: Mexican Americans had lower odds of treatment completion ( $O R=0.677 ; 95 \% \mathrm{Cl}=0.534,0.859)$ compared to non-Latino Whites. This disparity was explained in part by primary drug used, greater drug use severity, history of mental health disorders, and program acceptance of Medicaid payments. The interaction between Mexican Americans and acceptance of Medicaid was statistically significant $(O R=1.284 ; 95 \% \mathrm{Cl}=1.008,1.637)$.

Conclusions: Findings highlighted key program and client drivers of this disparity and the promising role of program acceptance of Medicaid payment to eliminate disparities in treatment completion among Mexican Americans. Implications for health policy during the Trump Administration are discussed.
\end{abstract}

Keywords: Disparities, Successful treatment completion, Racial and ethnic groups, Medicaid

\section{Background}

The current expansion of Medicaid in the United States to date has newly insured more than 16 million people and is playing an important role in reducing disparities in access to and engagement in care [1]. Insurance coverage is certainly the first step to reduce these disparities. But an often neglected factor that may contribute to disparities in access and engagement in care is provider

\footnotetext{
* Correspondence: erickgue@usc.edu

${ }^{1}$ Suzanne Dworak-Peck School of Social Work and Marshall School of Business, University of Southern California, 655 West 34th Street, Los Angeles, CA 90089, USA

Full list of author information is available at the end of the article
}

acceptance of Medicaid [2]. Because the current health care policy environment requires evidence to revise the Affordable Care Act (ACA), it is critical to examine the role of Medicaid in eliminating health care disparities [1].

Regarding substance use disorder (SUD) treatment, much of the research on disparities has focused on differences between Whites and African Americans with regard to service access and use [3, 4], with only limited attention given to disparities in SUD treatment outcomes between non-Latino Whites and Latinos [5]. This represents an important gap in public health knowledge in an era of health care reform during which Latinos, particularly Mexican Americans, represent the largest 
population of uninsured individuals $[6,7]$ and most critically underserved ethnic minority group in the United States $[8,9]$. Hence, we sought to identify individual and program characteristics associated with disparities in treatment completion.

This research is timely and can inform SUD treatment policy regarding the benefits and challenges of Medicaid as a mechanism to reduce the disparity gap in treatment completion. To support decision making related to the impact of Medicaid on quality of care, we sought to empirically assess the role of program acceptance Medicaid payment $[10,11]$ on reducing ethnic health care disparities, defined by the Institute of Medicine (recently renamed the National Academy of Medicine, or NAM) as all racial and ethnic differences except those due to clinical need, appropriateness, and patient preferences [12]. Establishing this relationship is important given three issues that challenge the health care system to improve quality of care for everyone: (a) the reduction or elimination of health-related disparities is a desired outcome in population health $[1,13-15]$ and would benefit any society; (b) empirical evidence regarding the impact of Medicaid expansion on health outcomes is extremely limited [16, 17]; and (c) lack of empirical evidence supporting Medicaid expansion is a barrier to justifying expansion efforts under the current administration [18].

In this study, we examined disparities and their drivers using rigorous statistical methods and critical theoretical frameworks. We relied on data from Los Angeles County's multimillion-dollar SUD treatment outcome system [19] and followed Kilbourne and colleagues' [20] three-phased disparities research framework, which includes a detection phase, understanding phase, and reduction phase. The purpose of the detection phase is to define health disparities, identify vulnerable populations, and develop valid measures for studying both. The purpose of the understanding phase is to identify factors that explain gaps in health and health care between vulnerable and less vulnerable groups, whereas the purpose of the reduction phase is to develop, implement, and/or evaluate interventions that may reduce or eliminate health and health care disparities. Consistent with this three-phased framework our three key research questions of interest were: Is there a disparity? What are the drivers of the disparity? Is Medicaid payment acceptance associated with reduction of the disparity? We completed the detection phase by examining the extent to which NAM-defined disparities exist between Mexican Americans and non-Latino Whites in terms of successful SUD treatment completion. We defined our outcome, successful treatment completion, as client report of sobriety at discharge, clinician report on clients' alcoholand drug-free status during the 30 days prior to discharge, and clinician decision to discharge clients successfully based on meeting treatment goals for that treatment episode. Second, we sought to complete the understanding phase by using a nonlinear adaptation of the OaxacaBlinder (OB) regression decomposition method [21, 22] to understand the factors underlying this disparity for Mexican Americans. This is a rigorous method to identify the extent to which differences between Mexican Americans and Whites in each of the covariates of interest explain the difference in treatment completion between these groups. Third, we sought to complete the reduction phase by testing the role of program acceptance of Medicaid payment in reducing the disparity by statistically testing differences in successful treatment completion between Mexican Americans and non-Latino Whites. This is the first study that relied on a large and unique multilevel dataset (programs and clients) to explore Mexican American disparities using advanced statistical methods, a framework to guide the disparities analysis, and theoretical frameworks to explain the client and program drivers of the disparity.

\section{Conceptual framework}

We relied on sociocultural [23] and resource dependence [24] theoretical frameworks to explain program and client factors associated with outcomes. Racial and ethnic disparities in service use are driven by racial and ethnic differences in both health care system factors (e.g., policy, provider organization, provider factors) and community system factors (e.g., social context, social cohesion, and patient factors) that accumulate during the course of an individual's illness. Stratified conditions are created when in the lower strata, health care markets fail, differential pathways into treatment develop, and there is poor patient-provider communication, lack of trust, and poor workforce availability or competence. As a result, racial and ethnic minorities have a greater risk than non-Latino Whites of dropping out of care and receiving lower quality of care, resulting in worse treatment outcomes [23, 25]. Thus in Hypothesis 1 regarding the detection phase, we posited that in both waves, after adjustment for clinical appropriateness and need, Mexican Americans will have lower rates of substance use treatment completion than non-Latino Whites.

Although the mechanisms of how these individual factors may inhibit Mexican Americans from successfully engaging in recovery have not been fully explored $[5,26]$, some empirical findings have suggested that these individual factors are negatively associated with treatment retention and posttreatment sobriety or abstinence $[3,5,26]$. In particular, disparate findings have suggested that these individual factors may create barriers to engaging fully in treatment and achieving sobriety or abstinence. Thus, in 
Hypothesis 2 regarding the understanding phase, we posited that the disparity will be driven by differences in individuals' drug use severity (number of days of use during the past 30 days at program intake), psychosocial stressors (i.e., history of mental health disorders), and program characteristics (e.g., licensing and accreditation).

Additionally, Latinos, in particular Mexican-Americans are most likely to access publicly funded SUD treatment programs with low quality of care and limited service resources $[4,5]$. Access to funding and technical support is critical for programs to improve quality of care, particularly among small and outpatient community-based treatment providers, which constitute more than $70 \%$ of the SUD treatment system [27-29]. SUD treatment organizations rely heavily on their regulatory and funding environment for financial and nonfinancial (i.e., professional expertise) resources, making them vulnerable to funding and regulatory expectations [30-32]. This is consistent with resource-dependence theory, which posits that high dependence on necessary resources determines an organization's priorities to respond to key stakeholders [24]. By accepting Medicaid payments, programs strategically increase their revenue due to an increased number of clients with Medicaid. However, accepting Medicaid payments also pressures programs to be accountable for positive client outcomes. Because the most promising program interventions emphasize the importance of Medicaid for guaranteeing access to and retention in behavioral health services among low-income Latino clients [2, 33, 34], Medicaid acceptance may potentially reduce outcome disparities. Medicaid payment acceptance is associated with Latinos' higher access to addiction treatment $[35,36]$, and for Mexican Americans this may lead to having the financial support to remain in treatment long enough to successfully complete treatment. Therefore, Medicaid payment acceptance may be especially beneficial for Mexican Americans by reducing treatment completion disparities; this will be assessed in moderation analyses by testing the significance of the coefficient for the Medicaid and Mexican American interaction term. Thus in Hypothesis 3 regarding the reduction phase, we posited that program acceptance of Medicaid payment will significantly reduce treatment disparities among Mexican Americans compared to programs not accepting Medicaid payments and non-Latino Whites.

\section{Methods}

\section{Sampling frame and data collection}

This study used a fully concatenated program and client dataset collected at two time points, 2010 and 2013. The sampling frame for program and client data included all SUD treatment programs funded by the Department of Public Health in Los Angeles County, California. Client data from these programs were drawn from the Los
Angeles County Participant Reporting System, which includes standardized scales and questions related to client admission, discharge, and health derived from state (California Outcome Measure System) and federal (Treatment Episode Data Set) measurement systems [19]. Of approximately 14,000 treatment episodes involving clients from all racial and ethnic minority groups each year, client data were restricted to non-Latino Whites (38\%) and Mexican Americans (32\%). The final sample featured data from 7305 client treatment episodes collected from January 1, 2010, to December 30, 2010, and 8107 client treatment episodes collected from January 1, 2013, to December 30, 2013. The average age of clients in our sample was 36 years and $63 \%$ were men; $53.7 \%$ were non-Latino Whites and $46.3 \%$ were Mexican Americans. See Table 1 for descriptive statistics.

These clients were drawn from a random sample of 147 publicly funded programs located in communities with a population of $40 \%$ or more Latino, primarily Mexican Americans or African American residents in Los Angeles County. Client data were merged with program survey data from program managers using program identification. The provider sample for 2010 consisted of 122 programs with full and verified information, whereas the 2013 data featured 112 programs. Sixty-one programs had data at both time points.

\section{Dependent variables}

\section{Successful SUD treatment completion}

This outcome relied on three indicators based on official discharge codes indicating whether clients successfully completed the major goals set forth in their recovery plan for that episode and whether clients reported sobriety at discharge. This dichotomous measure was coded 1 if clients met the following criteria: (a) the client reported no days of alcohol or drug use during the 30 days prior to discharge, (b) the clinician reported client sobriety at discharge, and (c) the clinician coded treatment episode as successful based on the client meeting treatment goals for that episode. This measure of treatment completion is more comprehensive than recent regional [37] and national [38] studies used in several analyses [39, 40].

\section{NAM framework-informed clinical appropriateness and service need}

This set of variables featured drug use severity at program entry (30-day drug use at intake), primary drug used, number of prior SUD treatment episodes, age at first drug use, and categorical measures of whether clients reported a history of mental health disorders or experienced homelessness at intake. 
Table 1 Program and client characteristics reported as count (percentage) or mean (standard deviation)

\begin{tabular}{|c|c|c|c|c|c|}
\hline & $\begin{array}{l}\text { Wave } 1(20 \\
(N=7305)\end{array}$ & & $\begin{array}{l}\text { Wave } 2(201 \\
(N=8107)\end{array}$ & & \\
\hline & White & Mexican American & White & Mexican American & $p^{a}$ \\
\hline Client variables & $(n=4050)$ & $(n=3255)$ & $(n=4232)$ & $(n=3875)$ & \\
\hline Treatment completion, $n(\%)^{*}$ & 749 (18.5) & $695(21.4)$ & $483(11.5)$ & $589(15.5)$ & $<.001$ \\
\hline Female, $n(\%)^{*}$ & $1529(37.8)$ & $1147(35.3)$ & $1666(39.4)$ & $1384(36.0)$ & .166 \\
\hline Age, $M(S D)$ & $38.1(12.9)$ & $34.4(11.7)$ & $38.8(13.1)$ & $34.9(12.3)$ & .011 \\
\hline Education, $n(\%)^{*}$ & & & & & $<.001$ \\
\hline Less than high school & $150(3.7)$ & $284(8.7)$ & $121(2.9)$ & $299(7.8)$ & \\
\hline High school & $2647(65.4)$ & $2612(80.3)$ & $680(16.1)$ & $1676(43.5)$ & \\
\hline College & $1174(29.0)$ & $347(10.7)$ & $2077(49.1)$ & 1497 (38.8) & \\
\hline Postgraduate & $79(2.0)$ & $12(0.4)$ & $1354(32.0)$ & $385(10.0)$ & \\
\hline Primary drug, $n(\%)^{*}$ & & & & & $<.001$ \\
\hline Heroin & $1251(30.9)$ & $652(20.0)$ & $1337(31.6)$ & $886(23.0)$ & \\
\hline Alcohol & $1144(28.3)$ & $678(20.8)$ & $1157(27.3)$ & $653(16.39)$ & \\
\hline Methamphetamine & $737(18.2)$ & $1111(34.1)$ & $918(21.7)$ & $1401(36.3)$ & \\
\hline Marijuana or hashish & $288(7.1)$ & $478(14.7)$ & $213(5.0)$ & $635(16.5)$ & \\
\hline Other & $630(15.6)$ & $336(10.3)$ & $607(14.3)$ & $282(7.3)$ & \\
\hline Days used, $M(S D)^{* b}$ & $16.0(13.0)$ & $11.1(12.8)$ & $18.1(12.8)$ & $12.5(13.1)$ & $<.001$ \\
\hline Age at first use, $M(S D)^{*}$ & $20.7(8.8)$ & $19.3(7.4)$ & $20.6(8.6)$ & $19.1(7.2)$ & .107 \\
\hline Medicaid eligible, $n(\%)^{*}$ & $988(24.4)$ & 997 (30.6) & $591(14.0)$ & $1186(30.8)$ & $<.001$ \\
\hline Mental health disorder, $n(\%)^{*}$ & $1380(34.1)$ & $612(18.8)$ & $1754(41.5)$ & $741(19.2)$ & $<.001$ \\
\hline Treatment type & & & & & $<.001$ \\
\hline Outpatient & $1635(40.4)$ & $1983(60.9)$ & $1257(29.7)$ & $2011(52.1)$ & \\
\hline Methadone & $162(4.0)$ & $159(4.9)$ & $226(5.3)$ & $301(7.8)$ & \\
\hline Residential & $2253(55.6)$ & $1113(34.2)$ & $2749(65.0)$ & $1545(40.1)$ & \\
\hline Program variables & $(n=122)$ & & $(n=112)$ & & \\
\hline Medicaid payment, $n$ (\%) & $85(70.8)$ & & $65(62.5)$ & & $<.001$ \\
\hline Licensed, $n$ (\%) & $115(85.0)$ & & $98(95.1)$ & & $<.001$ \\
\hline Accredited, $n(\%)^{c}$ & $20(16.8)$ & & $25(24.5)$ & & $<.001$ \\
\hline
\end{tabular}

Note: Percentages calculated after removing missing values

*Difference between ethnic groups within wave is statistically significant at $p<.051$

andicates statistical significance between waves

${ }^{\mathrm{b}}$ During 30 days prior to admission

${ }^{\mathrm{c} A c c r e d i t a t i o n}$ by the Joint Commission

\section{Medicaid insurance eligibility}

Clients and clinicians reported whether clients were eligible for Medicaid; these reports were obtained from admission data from the Los Angeles County Participant Reporting System in 2010 and 2013.

\section{Mexican American}

This categorical measure featured a dummy variable representing whether clients reported having a Mexican background regardless of generation in the United States $(1=$ Mexican American; 0 = not Mexican American $)$, with non-Latino Whites, also referred here as Whites, as the referent.

\section{Demographic covariates}

These covariates included client age, gender, and education.

\section{Program covariates}

These covariates indicated (a) whether the program accepted Medicaid payment; (b) whether the program was part of a parent organization or a standalone program; (c) whether the program was licensed by the state; (d) percentage of public funding received in the previous fiscal year; and (e) percentage of staff with graduate degrees. 


\section{Analytic strategy}

The detection phase identified ethnic disparities in substance use treatment completion following a three-step process informed by the NAM definition of health care disparities [41-43]: (a) model estimation; (b) a rank-andreplace methodology that adjusts for variables related to clinical appropriateness and need; and (c) prediction of rates of successful treatment completion for each racial and ethnic group using coefficients from Step 1 and adjusted characteristics from Step 2. In Step 1, a multiple logistic regression model was fitted to estimate the independent correlates of treatment completion. The logistic regression results are reported using odds ratios (ORs) and 95\% confidence intervals (CIs). In Step 2, we used the rank-and-replace adjustment approach to create a counterfactual population of Mexican Americans with the distribution of need variables for non-Latino Whites. Clinical appropriateness and need variables were adjusted and used to calculate the disparity, whereas other variables such as key program measures (e.g., license, accreditation, Medicaid payment acceptance) were treated as non-need-related system-level variables that were not adjusted and therefore did not influence the disparity calculation. For more details regarding this method, please refer to Cook et al. [42].

Finally, Step 3, the prediction of sobriety at treatment completion for each ethnic group, used coefficients from the original multivariate regression model (Step 1) and the adjusted need covariate values (Step 2). The mean of these predictions was subtracted from the mean of predictions for non-Latino White clients to estimate a metric value of disparity. Variance estimates accounted for both the complex sampling design and multiple imputation of missing data (less than $8 \%$ ). Variance estimates for disparity comparisons were calculated using a bootstrap procedure [44].

The understanding phase examined the association of individual- and program-level factors with treatment outcome disparities. Using the Fairlie variance decomposition method for nonlinear models [21], an extension of the OB decomposition method $[45,46]$, we estimated how much of the total difference in treatment completion between the two ethnic groups could be accounted for by each of the independent variables, while holding constant the other independent variables [22]. These analyses accounted for the clustering of clients within treatment facilities, adjusting standard errors for the correlation among clients of the same facilities $[4,38]$.

The reduction phase used the aforementioned multilevel logistic regression analysis to examine whether Medicaid payment acceptance was differentially beneficial (and disparity reducing) for Mexican Americans compared to whites. We relied on the STROBE statement to report all manuscript items required in rigorous observational studies.

\section{Results}

Table 1 shows different percentages of unadjusted successful treatment completion, comparing ethnic groups and waves. In both waves, Mexican Americans had higher unadjusted rates of completion than nonLatino Whites (21.4 vs. $18.5 \%$ in 2010 and $15.5 \%$ vs. $11.5 \%$ in 2013 , respectively).

Supporting Hypothesis 1, in the detection phase we found disparities in treatment completion in both waves after adjustment for clinical appropriateness and need, with Mexican Americans (13.3\%) having lower rates of substance use treatment completion than non-Latino Whites (14.4\%; $t$-test: Mexican Americans: $M=0.13$, $S D=0.01$ vs. Whites: $M=0.14, S D=0.00, p<.001)$. The absolute difference is $1.1 \%$, which corresponds to a relative decrease of $7.6 \%$ in the completion rate for Mexican Americans in relation to Whites. See Fig. 1. After further adjustment for the remaining individual socioeconomic and program factors in a multilevel logistic regression, compared to non-Latino Whites, Mexican Americans had significantly lower odds of treatment completion $(O R=0.677 ; 95 \% \mathrm{CI}=0.534,0.859)$. See Table 2.

Partial support for Hypothesis 2 was found. In the understanding phase, we posited that the disparity would be driven by differences in individuals' drug use severity (number of days of use during the past 30 days at program intake), psychosocial stressors (i.e., history of mental health disorders), and program characteristics (e.g., Medicaid payment acceptance, licensing, and accreditation). The results of the variance decomposition analysis in Table 3 describe the contribution of each of the covariates to the unadjusted Mexican Americanwhite difference in treatment completion. It is important to note that the Mexican American rate of treatment completion was higher than the White rate in the

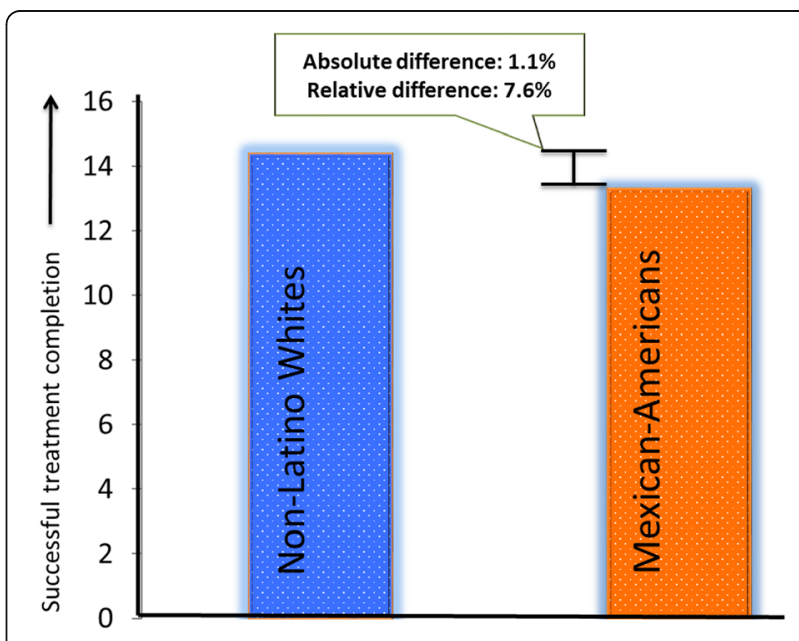

Fig. 1 Disparity in successful treatment completion 
Table 2 Multilevel logistic regression of successful treatment completion

\begin{tabular}{|c|c|c|c|c|}
\hline & OR & SE & $95 \% \mathrm{Cl}$ & $p$ \\
\hline \multicolumn{5}{|l|}{ Program variables } \\
\hline Wave $2^{\mathrm{a}}$ & 0.479 & 0.062 & $0.372,0.616$ & $<.001$ \\
\hline Medicaid payment & 0.487 & 0.079 & $0.355,0.668$ & $<.001$ \\
\hline Licensed & 1.745 & 0.423 & $1.085,2.806$ & .002 \\
\hline Accredited $^{b}$ & 1.034 & 0.219 & $0.682,1.567$ & .876 \\
\hline \multicolumn{5}{|l|}{ Cross-level interaction } \\
\hline Wave $\times$ Mexican American & 1.161 & 0.131 & $0.931,1.447$ & .186 \\
\hline Medicaid $\times$ Mexican American & 1.284 & 0.159 & $1.008,1.637$ & .043 \\
\hline \multicolumn{5}{|l|}{ Client variables } \\
\hline Mexican American & 0.677 & 0.082 & $0.534,0.859$ & .001 \\
\hline Female & 0.932 & 0.075 & $0.796,1.090$ & .379 \\
\hline Age & 1.007 & 0.004 & $1.000,1.014$ & .062 \\
\hline Education level & 1.010 & 0.048 & $0.920,1.108$ & .839 \\
\hline \multicolumn{5}{|l|}{ Primary drug ${ }^{c}$} \\
\hline Alcohol & 1.675 & 0.211 & $1.308,2.145$ & $<.001$ \\
\hline Methamphetamine & 1.777 & 0.321 & $1.247,2.532$ & .001 \\
\hline Marijuana or hashish & 1.689 & 0.252 & $1.260,2.264$ & $<.001$ \\
\hline Other & 1.744 & 0.221 & $1.361,2.237$ & $<.001$ \\
\hline Days used ${ }^{d}$ & 0.954 & 0.010 & $0.936,0.973$ & $<.001$ \\
\hline Age at first use & 0.998 & 0.006 & $0.986,1.011$ & .793 \\
\hline Medicaid eligibility & 0.878 & 0.105 & $0.695,1.111$ & .279 \\
\hline Mental health disorder & 0.764 & 0.054 & $0.665,0.878$ & $<.001$ \\
\hline \multicolumn{5}{|l|}{ Treatment type $e^{e}$} \\
\hline Methadone & 0.186 & 0.085 & $0.076,0.456$ & $<.001$ \\
\hline Residential & 0.791 & 0.148 & $0.548,1.141$ & .209 \\
\hline No. of programs & 143 & & & \\
\hline No. of clients & 14,934 & & & \\
\hline
\end{tabular}

Standard error values based on bootstrap method

${ }^{a}$ Wave 1 (2011) used as reference

${ }^{\mathrm{b}}$ Accreditation by the Joint Commission

'Heroin used as reference

${ }^{\mathrm{d}}$ During 30 days prior to admission

eoutpatient used as reference

unadjusted comparison. Nonetheless, the decomposition allows for the identification of significant factors underlying differences between Mexican Americans and Whites. The O-B decomposition approach identified the contribution of each covariate to the unadjusted difference in mean treatment completion between Mexican Americans and Whites. Programs' accepting Medicaid payments was a significant contributor to the unadjusted difference $(b=0.013 ; S E=0.005)$. Other significant contributors were ethnic differences in rates of use of alcohol $(b=-0.005 ; S E=0.001)$; methamphetamine $(b=0.009 ; S E=0.003)$; marijuana $(b=0.005 ; S E=0.002)$; and other drugs $(b=-0.003 ; S E=0.001)$. See Table 3.
Table 3 Multilevel Oaxaca-blinder decomposition of differences for Mexican Americans and non-latino whites in treatment completion

\begin{tabular}{lllll}
\hline & $b$ & SE & $95 \% \mathrm{Cl}$ & $p$ \\
\hline Overall & & & & \\
Mexican American & 0.175 & 0.022 & $0.132,0.218$ & $<.001$ \\
White & 0.144 & 0.026 & $0.093,0.196$ & $<.001$ \\
Difference & 0.031 & 0.021 & $-0.012,0.073$ & .154 \\
Explained & 0.069 & 0.019 & $0.031,0.106$ & $<.001$ \\
Unexplained & -0.038 & 0.014 & $-0.066,-0.010$ & .009
\end{tabular}

Program variables

$\begin{array}{lllll}\text { Wave }^{\mathrm{a}} & -0.002 & 0.002 & -0.006,0.003 & .492\end{array}$

$\begin{array}{lllll}\text { Medicaid payment } \quad 0.013 & 0.005 & 0.003,0.023 & .009\end{array}$

$\begin{array}{lllll}\text { Licensed } \quad 0.000 & 0.001 & -0.001,0.002 & .669\end{array}$

$\begin{array}{lllll}\text { Accredited }^{b} & -0.001 & 0.006 & -0.012,0.010 & .857\end{array}$

Cross-level interaction

$\begin{array}{lllll}\text { Wave } \times \text { Mexican American } \quad 0.008 & 0.007 & -0.005,0.021 & .230\end{array}$

Medicaid $\times$ Mexican American $0.015 \quad 0.008 \quad-0.001,0.032 \quad .065$

Client variables

$\begin{array}{lllll}\text { Female } & 0.000 & 0.000 & 0.000,0.001 & .458\end{array}$

Age $\quad-0.003 \quad 0.002 \quad-0.006,0.001 \quad .147$

Education level $\quad 0.000 \quad 0.002 \quad-0.005,0.004 \quad .843$

Primary drug ${ }^{c}$

Alcohol $\quad-0.0050 .001-0.008,-0.002<.001$

$\begin{array}{lllll}\text { Methamphetamine } & 0.009 & 0.003 & 0.004,0.015 & .001\end{array}$

$\begin{array}{lllll}\text { Marijuana or hashish } & 0.005 & 0.002 & 0.002,0.008 & .003\end{array}$

Other $\quad-0.003 \quad 0.001-0.005,-0.002<.001$

$\begin{array}{lllll}\text { Days used }^{d} & 0.025 & 0.010 & 0.006,0.044 & .012\end{array}$

$\begin{array}{llllll}\text { Age at first use } \quad 0.000 & 0.001 & -0.001,0.002 & .714\end{array}$

Medicaid eligibility $\quad-0.001 \quad 0.002-0.004,0.002 \quad 345$

$\begin{array}{lllll}\text { Mental health disorder } & 0.005 & 0.002 & 0.002,0.009 & .006\end{array}$

Treatment type ${ }^{\mathrm{e}}$

$\begin{array}{lllll}\text { Methadone } & -0.003 & 0.003 & -0.009,0.003 & .296\end{array}$

$\begin{array}{lllll}\text { Residential } & 0.005 & 0.004 & -0.002,0.013 & .154\end{array}$

${ }^{a}$ Wave 1 (2011) used as reference

${ }^{\mathrm{b}}$ Accreditation by the Joint Commission

'Heroin used as reference

${ }^{\mathrm{d}}$ During 30 days prior to admission

eOutpatient used as reference

The $1.1 \%$ disparity is explained by differences in programs accepting Medicaid payments, professional accreditation, client Medicaid eligibility and treatment type, and differences unexplained by model covariates

Support for Hypothesis 3 was found. In the reduction phase, we posited that program acceptance of Medicaid payment would significantly reduce treatment disparities among Mexican Americans compared to programs that did not accept Medicaid payments and non-Latino Whites. The interaction between Mexican Americans and programs' accepting Medicaid payment was statistically significant $(O R=1.284 ; 95 \% \mathrm{CI}=1.008,1.637)$, 
meaning that improvements in treatment completion for those treated in programs accepting Medicaid were greater for Mexican Americans than Whites.

\section{Discussion}

As summarized in Fig. 2, which builds upon Kilbourne and colleagues' [20] three-phased disparities research framework, the current study advances generalizable knowledge regarding three key questions. The extent to which disparities in successful SUD treatment completion exist between Mexican Americans and non-Latino Whites, which is the key identification phase question. The factors that explain disparities in SUD treatment completion between Mexican Americans and nonLatino Whites, which is the key understanding phase question. The extent to which variation in organization's Medicaid acceptance is related to reductions in the successful SUD treatment completion disparity between Mexican Americans and non-Latino Whites, which is one of the key reduction phase questions.

For our identification phase question, analyses that were adjusted for clinical appropriateness and need in accordance with the NAM definition of health care disparity, identified a significant disparity ( $1.1 \%$ difference) between Mexican Americans and non-Latino Whites in successful SUD treatment completion. This finding is significant given that it helps address the paucity of research on Mexican American disparities, which has been identified by the NAM as a priority in terms of precisely distinguishing differences among Latino subgroups to address their specific needs [12].

In the understanding phase, the sociocultural [23] and resource dependence [24] theoretical frameworks guided our investigation of contributors to treatment completion differences. In this phase, the O-B decomposition identified how underlying differences in individual and program factors contribute to the overall difference. For example, clients' primary drug of choice and programs' Medicaid payment acceptance were significant contributors to differences between Mexican-Americans and non-
Latino whites, whereas gender and age differences were negligible contributors. Specific findings of importance include: a) adjusting for Mexican Americans' rates of substance use (alcohol + meth + marijuana + other drugs $=-0.5 \%+0.9 \%+0.5 \%-0.3 \%=-0.6 \%)$ reduced Mexican American treatment completion rates and exacerbated the disparity by $0.9 \%$, b) adjusting for Mexican American and White differences in days of drug use at program intake increased Mexican American treatment completion rates and reduced the disparity by $3.3 \%$, and c) adjusting for Mexican American and White differences in history of mental illness increased Mexican American treatment completion rates and reduced the disparity by $0.5 \%$. These findings are especially significant given that they highlight the critical importance of adjusting for clinical characteristics when considering how well a treatment system is supporting minority individuals in care.

Finally, for our reduction phase question, which focused on organizations acceptance of Medicaid payment, results indicated that this payment were associated with significant decreases in the disparity between Mexican Americans and non-Latino Whites regarding successful completion of SUD treatment. In other words, improvements in treatment completion for those treated in programs accepting Medicaid payment were greater for Mexican Americans than non-Latino Whites, suggesting that these programs were especially successful in assisting Mexican Americans in overcoming barriers to successful treatment completion during a significant period of time (2011-2013) in which expansion of Medicaid began to develop in California. This finding is of tremendous significance because it simultaneously advances Mexican American disparities research [5] and adds to emerging information on the impact of pre-Medicaid expansion on treatment outcomes [17, 41]. Furthermore, Los Angeles County will implement a comprehensive waiver program in July 2017 regardless of federal legislation on health care reform. Thus, the current findings support the waiver's investment in Medi-Cal (California's Medicaid program) for funding and service delivery

\begin{tabular}{|c|c|c|}
\hline \begin{tabular}{l}
\multicolumn{1}{c}{$\begin{array}{c}\text { Detection } \\
\text { Phase }\end{array}$} \\
Finding: Relative to non- \\
Latino Whites, Mexican \\
Americans had a relative \\
decrease of $7.6 \%$ in \\
successful SUD treatment \\
completion (i.e., a \\
significant disparity).
\end{tabular} & $\begin{array}{l}\quad \begin{array}{l}\text { Understanding } \\
\quad \text { Phase }\end{array} \\
\text { Finding: The disparity in } \\
\text { successful SUD treatment } \\
\text { completion between } \\
\text { Mexican Americans and } \\
\text { non-Latino Whites seems to } \\
\text { be attributed to a) } \\
\text { differences in drug use at } \\
\text { intake, b) rates of substance } \\
\text { use, and c) history of } \\
\text { mental illness. }\end{array}$ & $\begin{array}{l}\quad \text { Reduction } \\
\quad \text { Phase } \\
\text { Finding: Supporting } \\
\text { organizations acceptance of } \\
\text { Medicaid, improvements in } \\
\text { successful SUD treatment } \\
\text { completion for those } \\
\text { treated in programs } \\
\text { accepting Medicaid were } \\
\text { greater for Mexican } \\
\text { Americans than non-Latino } \\
\text { Whites. }\end{array}$ \\
\hline
\end{tabular}

Fig. 2 Findings using the three-phases of health disparities research from Kilbourne and colleagues [20] 
regulation and individual characteristics of populations at higher risk of treatment dropout to improve treatment outcomes.

\section{Strengths and limitations}

The main strength of this study is its reliance on unique and robust data from Mexican Americans and non-Latino Whites to identify the importance of adjusting for clinical characteristics to accurately identify and potentially reduce disparities. The large data on programs and clients drawn from a real-world health care system and the application of rigorous NAM and $\mathrm{OB}$ approaches added explanatory power to identify, understand, and reduce disparities.

However, the limitations of the study should be considered when interpreting results. In our disparities measurement, we did not adjust for patient preferences. Other studies have discussed the problematic elicitation of fully informed patient preferences. Nonetheless, to the extent that these preferences contributed to the disparity, our calculations were not completely concordant with the breadth of the NAM definition of health care disparity. Other measures (discrimination, structural barriers to completion, and organizational cultural competence) have been shown to contribute to health care disparities [3-5] and were unobserved in our data. Future studies should incorporate these variables if possible. Another limitation includes analyzing administrative client data and program survey data, but the accuracy and reliability of these data were enhanced by triangulating these data with observational data obtained during site visits. This resulted in dropping $5 \%$ of programs with inconsistent information. Additionally, operationalization of success based on client self-reported 30-day alcohol- and drug-free status and clinician-reported client sobriety at successful treatment completion also could be improved. This outcome is also limited to a single treatment episode and does not consider that SUD treatment relies on a continuum-of-care approach. However, using two waves of data allowed us to provide robust results. Although the two-wave data did not allow us to establish causality, and differences in samples described in the Methods section may challenge the accuracy of changes reported at Wave 2, the sampling frame did not change and there were no statistically significant differences between and within programs in terms of reports of treatment completion. Finally, our analyses only allow us to generalize findings about service delivery to our sampling frame and not the wider addiction health services system. Nonetheless, this issue was somewhat mitigated by our large sample with two data collection time points of publicly funded SUD treatment programs serving communities with a population of $40 \%$ or more Latino, primarily Mexican-American or African American residents or both, representing approximately 7.7 million residents in Los Angeles County.

\section{Conclusion}

The present study provided evidence supporting the relationship between a treatment program's acceptance of Medicaid payments and treatment outcomes, especially in terms of having the potential to reduce important health disparities. Although further research is needed regarding both disparities for Mexican Americans and the impact of Medicaid on successful treatment outcomes, the present study nonetheless addressed significant gaps in the extant literature. This study provides evidence to support existing Medicaid coverage efforts, which again has been noted as a "critical piece of unfinished business" [1], and offers an opportunity to build on such efforts to promote health equity in California.

Because the ACA's main principles of achieving universal health care and enhancing access to affordable and quality care for all Americans [14] are currently being debated under the current political administration, future research should explore how revised Medicaid coverage or other health insurance policies may affect the significant progress of reducing the uninsurance rate by $43 \%$ [1] and consequential effects on access to and benefit of high-quality care shown in some studies $[6,11,36,47]$. In California, the new waiver program to be implemented in November 2017 will support the main principles of the ACA regarding access to care regardless of their potential federal repeal. It will be critical for researchers to track progress in treatment completion among the most vulnerable low-income and severely uninsured populations in California to inform national policy on the ultimate goal of improving public health for all.

\section{Abbreviations \\ ACA: Affordable care act; Cl: Confidence interval; NAM: National academy of medicine; OB: Oaxaca-blinder variance decomposition; OR: Odds ratio; SUD: Substance use disorder}

\section{Acknowledgements}

The authors would like to thank treatment providers for their participation in this study and appreciate Dr. Gary Tsai and Dr. Tina Kim from the Los Angeles County Department of Public Health, Substance Abuse Prevention and Control for their support. We also would like to acknowledge Eric Lindberg, from the School of Social Work at University of Southern California, for proofreading this paper.

\section{Funding}

Support for this research and manuscript preparation was provided by a National Institute of Drug Abuse research grant (R01 DA038608, CoPIs: Erick Guerrero and Bryan Garner) and an implementation fellowship training grant (R25 MH080916, PI: Enola Proctor). Neither of these two institutions had any further role in study design; in the collection, analysis, and interpretation of data; in the writing of the manuscript; or in the decision to submit the manuscript for publication.

\section{Availability of data and materials}

The datasets used and/or analyzed during the current study are available from the corresponding author and with permission of the Los Angeles County Department of Public Health on reasonable request. 


\section{Authors' contributions}

EG reviewed the research literature, framed the scope of the paper, contributed to the statistical analysis, and was the primary text author. BG, $B C$ and YK provided additional literature review, critical review of statistical analysis, and support in writing the manuscript, including revisions. WV and LG provided critical review and support for all revisions. All authors reviewed and approved the final draft.

\section{Competing interests}

The authors declare that they have no competing interests.

\section{Consent for publication}

Not applicable.

\section{Ethics approval and consent to participate}

This study was reviewed and approved by the Institutional Review Board of the University of Southern California (UP-13-00030). The principal investigator, also the corresponding author, has obtained consent to publish from the participants in this study (treatment clients and program staff members).

\section{Author details}

${ }^{1}$ Suzanne Dworak-Peck School of Social Work and Marshall School of Business, University of Southern California, 655 West 34th Street, Los Angeles, CA 90089, USA. ${ }^{2}$ RTI, 3040 East Cornwallis Road, Durham, NC 27709, USA. ${ }^{3}$ Department of Psychiatry, Harvard Medical School, 2 West Room 305, 401 Park Drive, Boston, MA 02215, USA. ${ }^{4}$ Mihaylo College of Business and Economics, California State University, Fullerton, Fullerton, CA 90089, USA. ${ }^{5}$ Department of Preventive Medicine, Keck School of Medicine, and Suzanne Dworak-Peck School of Social Work, University of Southern California, 655 West 34th Street, Los Angeles, CA 90089, USA. ${ }^{6}$ Department of General Medicine, University of California, Los Angeles, Los Angeles, CA 90025, USA.

\section{Received: 29 March 2017 Accepted: 19 May 2017}

\section{Published online: 25 May 2017}

\section{References}

1. Obama B. United States health care reform: progress to date and next steps. JAMA. 2016;316:525-32. doi:10.1001/jama.2016.9797.

2. Guerrero EG. Enhancing access and retention in substance abuse treatment: the role of Medicaid payment acceptance and cultural competence. Drug Alcohol Depend. 2013;132:555-61. doi:10.1016/j.drugalcdep.2013.04.005.

3. Guerrero EG, Marsh JC, Duan L, Oh C, Perron B, Lee B. Disparities in completion of substance abuse treatment between and within racial and ethnic groups. Health Serv Res. 2013;48:1450-67. doi:10.1111/1475-6773.12031.

4. Marsh JC, Cao D, Guerrero EG, Shin HC. Need-service matching in substance abuse treatment: racial/ethnic differences. Eval Program Plann. 2009;32:43-51. doi:10.1016/j.evalprogplan.2008.09.003.

5. Guerrero EG, Marsh JC, Khachikian T, Amaro H, Vega WA. Disparities in Latino substance use, service use, and treatment: implications for culturally and evidence-based interventions under health care reform. Drug Alcohol Depend. 2013;133:805-13. doi:10.1016/j.drugalcdep.2013.07.027.

6. Courtemanche C, Marton J, Ukert B, Yelowitz A, Zapata D. Impacts of the Affordable Care Act on health insurance coverage in Medicaid expansion and non-expansion states. National Bureau of Economic Research Working Paper No. 22182. 2016. http://www.nber.org/papers/w22182. Accessed 14 Aug 2016.

7. Kaiser Family Foundation. Health coverage for the Hispanic population today and under the Affordable Care Act. Fact Sheet No. 8432. 2013. http://kff.org/disparities-policy/report/health-coverage-for-the-hispanicpopulation-today-and-under-the-affordable-care-act. Accessed 24 Aug 2016.

8. Carrasquillo O, Carrasquillo Al, Shea S. Health insurance coverage of immigrants living in the United States: differences by citizenship status and country of origin. Am J Public Health. 2000;90:917-23. doi:10.2105/AJPH.90.6.917.

9. Derose KP, Escarce JJ, Lurie N. Immigrants and health care: sources of vulnerability. Health Aff. 2007;26:1258-68. doi:10.1377/hlthaff.26.5.1258

10. Kaiser Commission on Medicaid and the Uninsured. California's "Bridge to Reform" Medicaid demonstration waiver. Kaiser Family Foundation. 2011. http://kaiserfamilyfoundation.files.wordpress.com/2013/01/8197-r.pdf. Accessed 16 Jun 2016.
11. Sommers B, Arntson E, Kenney G, Epstein A. Lessons from early Medicaid expansions under the Affordable Care Act. 2013. http://healthaffairs.org/ blog/2013/06/14/lessons-from-early-medicaid-expansions-under-theaffordable-care-act. Accessed 16 Jun 2016.

12. Institute of Medicine. Unequal treatment: confronting racial and ethnic disparities in health care. Washington, DC: National Academies Press; 2002.

13. Agency for Healthcare Research and Quality. Disparities in healthcare quality among racial and ethnic groups: selected findings from the 2011 National Healthcare Quality and Disparities Reports. http://www.ahrq.gov/research/ findings/nhqrdr/nhqrdr11/minority.html. Accessed 12 Jul 2016.

14. Andrulis DP, Siddiqui NJ, Purtle JP, Duchon L. Patient Protection and Affordable Care Act of 2010: advancing health equity for racially and ethnically diverse populations. Washington, DC: Joint Center for Political and Economic Studies; 2010.

15. Ulmer C, McFadden B, Nerenz DR, editors. Race, Ethnicity, and Language Data: Standardization for Health Care Quality Improvement. Washington, D.C.: The National Academies Press; 2009.

16. Paradise J, Garfield R. What is Medicaid's impact on access to care, health outcomes, and quality of care? setting the record straight on the evidence. Kaiser Commission on Medicaid and the Uninsured. 2013. http://kff.org/ report-section/what-is-medicaids-impact-on-access-to-care-healthoutcomes-and-quality-of-care-setting-the-record-straight-on-the-evidenceissue-brief. Accessed 13 Sep 2016.

17. Seibert J, Fields S, Fullerton CA, Mark TL, Malkani S, Walsh C, et al. Use of quality measures for Medicaid behavioral health services by state agencies: implications for health care reform. Psychiatr Serv. 2015;66:585-91. doi:10.1176/appi.ps.201400130.

18. Andrews CM. The relationship of state Medicaid coverage to Medicaid acceptance among substance abuse providers in the United States. J Behav Health Serv Res. 2014;41:460-72. doi:10.1007/s11414-013-9387-2.

19. Crèvecoeur D, Finnerty B, Rawson RA. Los Angeles County Evaluation System (LACES): bringing accountability to alcohol and drug abuse treatment through a collaboration between providers, payers, and researchers. J Drug Issues. 2002;32:865-79. doi:10.1177/ 002204260203200309

20. Kilbourne AM, Switzer G, Hyman K, Crowley-Matoka M, Fine MJ. Advancing health disparities research within the health care system: a conceptual framework. Am J Public Health. 2006;96:2113-21. doi:10.2105/AJPH.2005.077628.

21. Fairlie RW. An extension of the Blinder-Oaxaca decomposition technique to logit and probit models. J Econ Soc Meas. 2005;30:305-16.

22. Field GS. Accounting for income inequality and its change: a new method, with application to the distribution of earnings in the United States. ILR School, Cornell University. 2002. http://digitalcommons.ilr.cornell.edu/ articles/265. Accessed 16 Oct 2012.

23. Alegría M, Pescosolido BA, Canino G. A socio-cultural framework for mental health and substance abuse service disparities. In: Sadock BJ, Sadock VA, Ruiz P, editors. Kaplan \& Sadock's comprehensive textbook of psychiatry. 9th ed. Philadelphia: Lippincott Williams \& Wilkins; 2009. p. 4370-9.

24. Pfeffer J, Salancik GR. The external control of organizations. New York: Harper \& Row; 1978.

25. Alegría M, Pescosolido BA, Williams S, Canino G. Culture, race/ethnicity and disparities: fleshing out the socio-cultural framework for health service disparities. In: Pescosolido BA, Martin JK, McLeod JD, Rogers A, editors. Handbook of the sociology of health, illness, and healing. New York: Springer; 2011. p. 363-82.

26. Chartier KG, Caetano R. Trends in alcohol services utilization from 1991-1992 to 2001-2002: ethnic group differences in the U.S. population. Alcohol Clin Exp Res. 2011;35:1485-97. doi:10.1111/j.1530-0277.2011.01485.x.

27. Blue Ribbon Task Force on NIDA Health Services Research. Report of the Blue Ribbon Task Force on Health Services Research at the National Institute on Drug Abuse. Bethesda: National Institute on Drug Abuse; 2010.

28. MacMaster SA, Holleran LK, Chantus D, Kostyk L. Documenting changes in the delivery of substance abuse services: the status of the "100 best treatment centers for alcoholism and drug abuse" of 1988. J Health Soc Policy. 2005;20:67-77. doi:10.1300/J045v20n03_04.

29. McLellan AT, Carise D, Kleber HD. Can the national addiction treatment infrastructure support the public's demand for quality care? J Subst Abus Treat. 2003:25:117-21. doi:10.1016/S0740-5472(03)00156-9.

30. Campbell Cl, Alexander JA. Health services for women in outpatient substance abuse treatment. Health Serv Res. 2005:40:781-810. doi:10.1111/j.1475-6773.2005.00385.x. 
31. D'Aunno TA. The role of organization and management in substance abuse treatment: review and roadmap. J Subst Abus Treat. 2006;31:221-33. doi:10.1016/j.jsat.2006.06.016.

32. Guerrero EG. Managerial capacity and adoption of culturally competent practices in outpatient substance abuse treatment organizations. J Subst Abus Treat. 2010;39:329-39. doi:10.1016/j.jsat.2010.07.004.

33. Alegría M, Page JB, Hansen H, Cauce AM, Robles R, Blanco C, et al. Improving drug treatment services for Hispanics: research gaps and scientific opportunities. Drug Alcohol Depend. 2006;84:S76-84. doi:10.1016/j.drugalcdep.2006.05.009.

34. Vega, William A. Higher stakes ahead for cultural competence. Gral Hosp Psychi 27(6) (2005): 446-450.

35. Callahan JJ, Shepard DS, Beinecke RH, Larson MJ, Cavanaugh D. Mental health/substance abuse treatment in managed care: the Massachusetts Medicaid experience. Health Aff. 1995;14:173-84. doi:10.1377//lthaff.14.3.173.

36. Guerrero EG, Aarons GA, Grella CE, Garner BR, Cook B, Vega WA. Program capacity to eliminate outcome disparities in addiction health services. Adm Policy Ment Health Ment Health Serv Res. 2016;43:23-35. doi:10.1007/s10488-014-0617-6.

37. Jacobson JO, Robinson P, Bluthenthal RN. A multilevel decomposition approach to estimate the role of program location and neighborhood disadvantage in racial disparities in alcohol treatment completion. Soc Sci Med. 2007;64:462-76. doi:10.1016/j.socscimed.2006.08.032

38. Substance Abuse and Mental Health Services Administration. The TEDS Report: predictors of substance abuse treatment completion or transfer to further treatment, by service type. Rockville: Substance Abuse and Mental Health Services Administration, Office of Applied Studies; 2009.

39. Guerrero EG, Campos M, Urada D, Yang JC. Do cultural and linguistic competence matter in Latinos' completion of mandated substance abuse treatment? Subst Abuse Treat Prev Policy. 2012;7:34. doi:10.1186/1747-597X-7-34.

40. Guerrero EG, Cepeda A, Duan L, Kim T. Disparities in completion of substance abuse treatment among Latino subgroups in Los Angeles County CA. Addict Behav. 2012;37:1162-6. doi:10.1016/j.addbeh.2012.05.006.

41. Creedon TB, Cook B. Access to mental health care increased but not for substance use, while disparities remain. Health Aff. 2016;35:1017-21. doi:10.1377/hlthaff.2016.0098

42. Cook B, Manning W, Alegría M. Measuring disparities across the distribution of mental health care expenditures. J Ment Health Policy Econ. 2013;16:3-12

43. McGuire TG, Alegria M, Cook BL, Wells KB, Zaslavsky AM. Implementing the Institute of Medicine definition of disparities: an application to mental health care. Health Serv Res. 2006;41:1979-2005. doi:10.1111/j.1475-6773, 2006.00583.x.

44. Efron B. Bootstrap methods: another look at the jackknife. Ann Stat. 1979;7: 1-26. doi:10.1214/aos/1176344552.

45. Blinder AS. Wage discrimination: reduced form and structural estimates. J Hum Resour. 1973;8:436-55. doi:10.2307/144855.

46. Oaxaca R. Male-female wage differentials in urban labor markets. Int Econ Rev. 1973;14:693-709. doi:10.2307/2525981.

47. Andrews C, Abraham A, Grogan CM, Pollack HA, Bersamira C, Humphreys K, et al. Despite resources from the ACA, most states do little to help addiction treatment programs implement health care reform. Health Aff. 2015;34:828-35. doi:10.1377/hlthaff.2014.1330.

\section{Submit your next manuscript to BioMed Centra and we will help you at every step:}

- We accept pre-submission inquiries

- Our selector tool helps you to find the most relevant journal

- We provide round the clock customer support

- Convenient online submission

- Thorough peer review

- Inclusion in PubMed and all major indexing services

- Maximum visibility for your research

Submit your manuscript at www.biomedcentral.com/submit 